\title{
Cobertura de gotas de pulverização obtida com diferentes pontas e taxas de aplicação na parte aérea da cana-de-açúcar
}

\author{
Spray droplet coverage achieved with different nozzles and application rates in the aerial part \\ of sugar cane
}

\author{
Juliano Luiz Schneider ${ }^{*}$ Gustavo Migliorini de Oliveira ${ }^{\mathrm{I}}$ Rafael Esperidião Balan $^{\mathrm{II}}$ \\ Marcelo Giovanetti Canteri ${ }^{I}$ Otávio Jorge Grigoli Abi Saab ${ }^{\mathrm{I}}$
}

\section{RESUMO}

A aplicação de produtos fitosssanitários no setor sucroalcoleiro, até recentemente, estava focada principalmente no controle de plantas daninhas. Com o aparecimento da ferrugem alaranjada, como doença de importância agrícola na cultura da cana-de-açúcar, passou a ser imperioso conhecer como a aplicação chega na parte aérea da planta. Dessa forma, o presente estudo foi desenvolvido com o objetivo de avaliar a qualidade da deposição da calda em pulverização terrestre, conduzido em esquema fatorial $2 \times 2 \times 2$ (duas pontas de pulverização, duas taxas de aplicação e duas posições dos cartões de papéis hidrosensíveis no dossel da planta), seis repetições, com dez papéis cada. Foram utilizadas as pontas de pulverizacão XR110.02 (jato plano de uso ampliado) e TTJ60 - 110.02 (jato plano duplo, com ângulo de 60 graus entre si) utilizando-se as taxas de aplicação de 120 e $160 \mathrm{~L}$ $h a^{-1}$. Os cartões de papel hidrossensível utilizados para avaliar a deposicão das pulverizações foram distribuidos sobre as folhas de cana-de-açúcar, em duas posições distintas em relação ao dossel da planta (parte superior e inferior, aproximadamente, 0,80 e 0,50 metros do solo, dispostos na horizontal e inclinado em relação à superfície do solo, respectivamente). A cultivar utilizada foi 'RB 96-6928', com altura de 0,80m aos 120 dias do plantio. Um scaner de mesa foi utilizado para digitalizar as imagens dos papéis e avaliou-se as coberturas através do programa ContaGotas $^{\circledast}$. Os dados de deposição/cobertura foram submetidos à análise de variância e as médias comparadas pelo teste Tukey ao nível de $5 \%$ de probabilidade de erro. No dossel superior da canade-açúcar observou-se maior cobertura, quando comparado ao dossel inferior, sendo que não se observaram diferenças entre

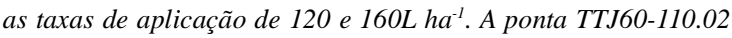
promoveu cobertura superior à ponta XR 110.02 quando se utilizou $160 \mathrm{~L} \mathrm{ha}^{-1}(40,34$ e 36,50\%, respectivamente).

Palavras-chave: Puccinia kuehnii, agrotóxicos, tecnologia de aplicação, volumes de pulverização, papéis hidrossensíveis.

\begin{abstract}
The terrestrial application of agricultural defensives in the sugar-alchool producer sector until recently was focused on weed control. After the appearance of orange rust, a disease of agricultural importance in sugar cane production, it has become imperative to know how the application arrives at the plant canopy. In such a way, the present study was developed with the objective of evaluate the quality of the deposition in terrestrial spraying, lead in factorial project $2 \times 2 \times 2$ (two nozzles of spraying, two rates of application and two positions of the water-sensitive papers in the canopy of plant), six repetitions, with ten papers each. It has been used the nozzles of spraying XR110.02 (plain jet of extended range) and TTJ60 - 110,02 (double plain jet, with angle of 60 degrees between itself) using the rates of application of 120 and $160 \mathrm{~L} \mathrm{ha}$. The water-sensitive papers cards used to evaluate the deposition of the sprayings had been distributed on the leaves of sugar cane in two distinct heights (upper and lower, approximately 0,80 and 0,50 meters above ground level, arranged in horizontal and inclined with respect to the road surface, respectively). A table scanner was used to generate the digital images of the papers and evaluated the coverings through the Conta-Gotas ${ }^{\circledR}$ program. The deposition data/covering had been submitted to the variance analysis and the averages compared with the Tukey test at 5\% of significance. It was observed in the superior canopy of the sugarcane a bigger covering when compared with the inferior, there was no difference between the

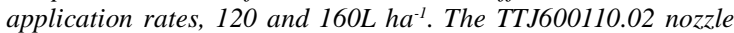
promoted bigger covering the XR110.02 nozzle when using $160 \mathrm{~L}$ $h a^{-1}(40,34$ and $36,50 \%$, respectively).
\end{abstract}

Key words: Puccinia kuehnii, pesticide, application technology, spray volume, water sensitive papers.

\section{INTRODUÇÃO}

A cana-de-açúcar destaca-se como principal fonte de biomassa energética, no que se

'Programa de Pós-graduação em Agronomia, Universidade Estadual de Londrina (UEL), 86050-620, Londrina, PR, Brasil. E-mail: rondo_agro@yahoo.com.br. *Autor para correspondência.

"Programa de graduação em Agronomia, UEL, Londrina, PR, Brasil. 
refere à produção de biocombustíveis, produzida no país. Vários são os fatores condicionantes e limitantes à sua produção, como, por exemplo, nutricionais, climáticos, genéticos e fitossanitários. No contexto do manejo fitossanitário da cultura, a aplicação de produtos químicos estava focada principalmente no controle de plantas daninhas e erradicação de soqueiras por hebicidas (SILVA et al., 2006) e pragas por inseticidas (PEREIRA et al., 2010). O fungo da espécie Puccinia kuehnni (W. Krüger) E.J. Butler é o patógeno causador da ferrugem alaranjada, que, num passado recente, apresentava distribuição limitada (Indonésia, Austrália, Índia e China), entretanto, ao final da década de 90, alastrou-se pelos canaviais da Austrália, causando sérios prejuízos ao setor açucareiro australiano (BRASIL, 2008).

O Ministério da Agricultura, Pecuária e Abastecimento (MAPA) notificou recentemente a primeira ocorrência na América do Sul da ferrugem alaranjada da cana-de-açúcar no Brasil, em Araraquara. O Departamento de Sanidade Vegetal da Secretaria de Defesa Agropecuária do MAPA (SDA/ DSV) oficializou a constatação do fungo no dia 5 de janeiro de 2010 (SCORALERT, 2010).

Dentre os métodos de controle disponiveis para a doença, o controle varietal é sem dúvida o método mais econômico e eficiente, mas, para se substituir as áreas com variedades suscetíveis, o processo não será rápido. Nesse meio tempo, fazse necessário estudos sobre o controle químico fungicida, vizando a minimizar possíveis prejuízos provocados por esse patógeno.

Baseado nesses aspectos, a tecnologia de aplicação é de grande importância, pois os produtos aplicados devem atingir de forma satisfatória o agente que se deseja controlar, dependendo, assim, da técnica empregada para isso (ZAMBOLIM et al., 2003). Segundo MATTHEWS (2002), o inuito da tecnologia de aplicação é colocar a quantidade certa de ingrediente ativo no alvo, com a máxima eficiência e de maneira econômica, afetando o mínimo possível o ambiente.

A forma tradicional de aplicação de produtos fitossanitários é, por meio de pulverizadores, dotados de pontas de pulverização hidráulicos. Essas pontas são os componentes mais significativos dos pulverizadores e apresentam, como funções básicas: fragmentar o líquido em pequenas gotas, distribuir as gotas em pequena área e controlar a saída do líquido por unidade de área (SIDAHMED, 1998).

O uso da pulverização na agricultura depende não somente de produtos de ação comprovada, mas também da tecnologia desenvolvida para sua aplicação. A pulverização fica, ainda, condicionada ao momento de sua realização e à influência dos fatores meteorológicos e biológicos. A eficiência da aplicação também é afetada pela forma, tamanho e posição do alvo, densidade, diâmetro e velocidade de gota e pela velocidade e direção do fluxo (BALAN et al., 2005).

Teoricamente, quanto menor o tamanho de gota produzida maior é o percentual de cobertura sobre o alvo, em função do maior número de gotas geradas, porém, também é maior o risco de evaporação e deriva para fora do alvo (ANTUNIASSI et al., 2004; TEIXEIRA, 1997). Isso torna, portanto, o tamanho de gota um importante fator a ser considerado em aplicações de produtos fitossanitários, uma vez que se objetiva alcançar o dossel da cultura de forma relativamente uniforme.

O volume de aplicação é um dos parâmetros fundamentais para o sucesso da aplicação (SANTOS, 2007). Sua definição depende das características do alvo a ser atingido, do tamanho das gotas, da cobertura necessária, dentre outros fatores. $\mathrm{O}$ volume de aplicação influencia também na capacidade operacional da operação, pois, quanto maior o volume de aplicação utilizado, maior será o número de paradas para reabastecimento do pulverizador e menor a área tratada por unidade de tempo pelo mesmo equipamento.

Tendo como hipótese a necessidade da aplicação de fungicida atingir a planta, diferente das aplicações de inseticida e herbicida, o objetivo deste trabalho foi avaliar o percentual de cobertura da calda em pulverização, em aplicação terrestre, em função de diferentes taxas de aplicação e pontas de pulverização, em duas posições do dossel da cultura da cana-de-açúcar, visando a auxiliar no manejo da ferrugem alaranjada.

\section{MATERIAL E MÉTODOS}

O presente trabalho foi desenvolvido em área comercial de cana-de-açúcar, localizada no município de Bandeirantes-PR, pertencente à Usina de Bandeirantes (2351'18' Sul, 50²0'15" Oeste), altitude de 420 metros e clima Subtropical Cfb (KÖPPEN \& GEIGER, 1928).

$\mathrm{O}$ estudo foi conduzido em esquema fatorial $2 \times 2 \times 2$ (duas pontas de pulverização, duas taxas de aplicação e duas posições dos papéis hidrossensíveis no dossel da planta), seis repetições, com dez papéis cada. Cada parcela foi composta de $280 \mathrm{~m}^{2}(14 \times 20 \mathrm{~m})$.

O equipamento utilizado para aplicação foi um trator marca Valtra, modelo BM100, equipado com 
tração dianteira auxiliar (não utilizada na realização do experimento), potência do motor $77,2 \mathrm{~kW}$, no qual foi acoplado um pulverizador marca Jacto, modelo Falcon Vortex, com tanques adicionais dispostos lateralmente ao trator, com capacidade volumétrica total de 1.400 litros de calda, barra de pulverização de 14,0m, dotada de 29 pontas hidráulicas distanciadas $0,5 \mathrm{~m}$ umas das outras. As pontas de pulverizacão utilizadas foram das séries XR110.02 (jato plano de uso ampliado) e TTJ60 - 110.02 (jato plano duplo, com ângulo de 60 graus entre si), ambas da marca TEEJET. Durante a pulverização, a barra foi conduzida $0,50 \mathrm{~m}$ acima do topo da cultura. $\mathrm{O}$ conjunto trator pulverizador deslocou-se a velocidade constante de $6 \mathrm{~km} \mathrm{~h}^{-1}$ e a calda aplicada constituiuse somente de água. Na tabela 1, estão descritos os tratamenos utilizados no experimento.

A cultivar de cana-de-açúcar utilizada foi 'RB 96-6928' e, no momento das aplicações dos tratamentos, as plantas apresentavam altura de $0,80 \mathrm{~m}$ aos 120 dias do plantio. As pulverizações ocorreram no dia 09/jun/2010, com início às 14h30min e término às $16 \mathrm{~h} 30 \mathrm{~min}$. Os fatores climáticos foram monitorados por um termohigroanemômetro Kestrel. A temperatura oscilou de 20 a $25^{\circ} \mathrm{C}$, a umidade relativa entre 40 e $50 \%$ e a velocidade do vento entre 1,5 e $4,5 \mathrm{~km} \mathrm{~h}^{-1}$.

Foram distribuidos cartões de papel hidrossensível que mediam $26 \times 76 \mathrm{~mm}$ sobre a face adaxial das folhas de cana-de-açúcar, fixados com grampeador, em duas posições distintas: no dossel superior (dispostos horizontalmente na face superior do ponto de curvatura da folha, situada a $0,80 \mathrm{~m}$ em relação ao solo) e inferior (dispostos inclinados na axila da folha, situada a $0,50 \mathrm{~m}$ em relação ao solo). Após as pulverizações, os cartões de papel hidrossensível foram recolhidos e fixados em folhas de papel sulfite, tamanho A4.

Os dados de porcentagem de cobertura dos papéis foram obtidos pela digitalização de cada cartão de papel hidrossensível em um scaner de mesa, com 300dpi de resolução, sendo as imagens processadas através do programa Conta-Gotas ${ }^{\circledR}$ (CANTERI et al., 2001). Os dados de deposição foram submetidos à análise de variância e as médias comparadas pelo teste Tukey em nível de $5 \%$ de probabilidade de erro.

\section{RESULTADOS E DISCUSSÃO}

A análise de variância fatorial indicou não existir interação tripla entre os fatores pontas de pulverização, taxas de aplicação e posições dos alvos, quanto à porcentagem de cobertura dos cartões de papel hidrossensível (Tabela 2). No entanto, ocorreu interação significativa somente entre os fatores pontas de pulverização e taxas de aplicação, sendo, portanto, a posição dos alvos independente dos demais fatores analisados.

A porcentagem de cobertura dos cartões de papel hidrossensível na parte superior do dossel das plantas $(0,80 \mathrm{~m})$ foi significativamente maior que a $0,50 \mathrm{~m}$, atingindo $46,08 \%$ da área total. Já na axila da folha $(0,50 \mathrm{~m})$, a cobertura porcentual foi de $30,65 \%$, correspondendo a um valor de cobertura $33,50 \%$ inferior, quando comparado à posição mais elevada. Os papéis locados no dossel superior das plantas possuem probabilidade maior de serem atingidos pelas gotas pulverizadas, visto que a distância que as gotas precisam percorrer para atingir a parte inferior do dossel é maior. É importante salientar que, no presente trabalho, os cartões de papéis hidrossensíveis dispostos na região superior estavam na posição horizontal, enquanto os inferiores estavam posicionados inclinados em relação à superfície do terreno, seguindo a arquitetura das plantas. Essa configuração também pode ter contribuído para a maior cobertura no dossel superior, decorrente da simulação da arquitetura foliar das plantas de cana-de-açúcar.

Segundo SOUZA et al. (2007), as folhas localizadas no terço inferior das plantas representam o alvo mais difícil de atingir em pulverizações. A sobreposição das folhas existentes no caminho das gotas e também a maior distância percorrida, além da maior possibilidade de perda por evaporação ou

Tabela 1 - Pontas de pulverização, pressões de trabalho, taxas de aplicação e tamanho de gota utilizadas nos tratamentos estudados.

\begin{tabular}{lccc}
\hline Pontas de pulverização & Pressões de trabalho $(\mathrm{kPa})$ & Taxa de aplicação $\left(\mathrm{L} \mathrm{ha}^{-1}\right)$ & Tamanho de gota \\
\hline \multirow{2}{*}{ XR 110.02} & 193 & 120 & Média \\
& 310 & 160 & Fina \\
TTJ60 110.02 & 193 & 120 & Grossa \\
& 310 & 160 & Grossa \\
\hline
\end{tabular}


Tabela 2 - Valores de probabilidade de F obtidos da análise de variância do fatorial ponta de pulverização x taxa de aplicação x posição no dossel para o percentual de cobertura nos cartões de papel hidrossensível.

\begin{tabular}{llc}
\hline Fonte de variação & F calculado & Pr> Fc \\
\hline Ponta de pulverização & 1,756 & $0,1858^{\text {ns }}$ \\
Taxa de aplicação & 0,001 & $0,9753^{\text {ns }}$ \\
Posição no dossel & 251,475 \\
Ponta de pulverização x taxa de aplicação & 6,775 & $0,0001^{* *}$ \\
Ponta de pulverização x posição no dossel & 0,305 & $0,0095^{* *}$ \\
Taxa de Aplicação x posição no dossel & 5,862 & $0,5811^{\text {ns }}$ \\
Ponta de pulverização x taxa de aplicação x posição no dossel & 1,575 & $0,0159^{\text {ns }}$ \\
CV(\%) & $0,2101^{\text {ns }}$ & 27,32 \\
\hline
\end{tabular}

** Significativo a $1 \%$ de probabilidade. ${ }^{\text {ns }}$ Não significativo a $5 \%$ de probabilidade.

deriva das gotas menores, em condições ambientais adversas, implicam menor número de gotas chegando ao alvo e irregularidade no volume depositado.

CUNHA et al. (2010), analisando a cobertura de gotas nos diferentes terços da planta de milho, cultura com arquitetura similar à da cana-deaçúcar, afirmou que, no dossel superior da cultura do milho, ocorreu maior porcentagem de cobertura e, no terço inferior, menor cobertura de gotas, o que já era esperado, uma vez que o terço superior encontra-se mais próximo ao ponto de lançamento da gota.

Os produtos sistêmicos translocam-se na planta via xilema (movimento acrópeta), ou seja, a translocação ocorre das partes inferiores para as partes superiores, seguindo o fluxo da transpiração. Esse é mais um fator que indica a importância em se atingir as partes mais baixas da planta, uma vez que as gotas que atingem as folhas mais expostas na parte superior do dossel não serão responsáveis pelo controle de doenças no baixeiro (ROMÁN et al., 2009).

GERARD et al. (1998), analisando a relação entre a arquitetura da planta de cevada e a interceptação da calda de pulverização, também verificaram que a concentração da calda na folha aumenta da folha-bandeira para as folhas mais velhas. Os autores concluem que a folha-bandeira possui maior angulação e que tal ângulo tende a se aproximar da horizontal, à medida que a folha vai envelhecendo, o que favorece a deposição de gotas.

No tocante a interação dupla significativa existente entre a ponta de pulverização e a taxa de aplicação (Tabela 3), nota-se que houve redução na porcentagem de cobertura somente quando do uso da taxa de aplicação de $160 \mathrm{~L} \mathrm{ha}^{-1}$ com relação a $120 \mathrm{~L}$ ha $^{-1}$ para a ponta de XR 110.02, não sendo verificado o mesmo para a ponta TTJ60 110.02. Porém, a redução foi relativamente pequena, em torno de $2,5 \%$ do percentual de cobertura das gotas. Na taxa de apliação de $120 \mathrm{~L} \mathrm{ha}^{-1}$, ambas as pontas proporcionaram os mesmos percentuais de cobertura estatisticamente.

ROMÁN et al. (2009), em estudos de aplicacão de fungicidas na cultura da soja, utilizaram três volumes de pulverização $(100,150$ e $200 \mathrm{~L}$ ha $^{-1}$ ), não encontrando diferença significativa na porcentagem de cobertura de fungicida, entretanto, observaram tendência de aumento com o incremento na taxa de aplicação.

A isonomia de porcentagem de cobertura dos alvos com os volumes de 120 e $160 \mathrm{~L} \mathrm{ha}^{-1}$, verificada neste estudo, permite inferir que haverá a mesma eficiência de controle, porém com maior rendimento operacional para o volume de $120 \mathrm{~L}$ ha $^{-1}$, além de economia de tempo e monetária ao longo do processo. O uso de menor volume de calda aumenta a autonomia e a capacidade operacional dos pulverizadores, podendo ser o principal componente do desempenho operacional em diversas culturas (ROMÁN et al., 2009).

A ponta TTJ60-110.02 proporcionou maior cobertura $(\mathrm{P}<0,05)$, em relação à ponta $\mathrm{XR}$ 110.02, somente na taxa $160 \mathrm{~L} \mathrm{ha}^{-1}$. Nesse caso, a maior cobertura porcentual pela ponta TTJ60-110.02 pode ser atribuída à manutenção do espectro de gotas na faixa de pressão utilizada (193 e 310kPa). Nesse tipo de ponta, também é importante destacar o efeito do duplo jato plano, com ângulo de $60^{\circ}$ entre si, na distribuição das gotas. Já no caso da ponta XR110.02, nas mesmas pressões de trabalho utilizadas, o padrão de gotas se altera de médias para finas (TEEJET, 2011), podendo comprometer a cobertura porcentual. Segundo TEIXEIRA (1997), gotas muito pequenas, na maioria das vezes, geram boa cobertura superficial 
Tabela 3 - Porcentagem de cobertura nos cartões de papel hidrossensivel em função da interação entre pontas de pulverização (TTJ60 110.02, XR 110.02) e taxa de aplicação $\left(\mathrm{L}^{\mathrm{h}} \mathrm{ha}^{-1}\right)$.

\begin{tabular}{lccc}
\hline & & & \\
Taxa de aplicação $\left(\mathrm{L}, \mathrm{ha}^{-1}\right)$ & & & \\
& TTJ60 110.02 & XR 110.02 & DMS \\
\hline 160 & $40,34 \mathrm{Aa}$ & $36,50 \mathrm{Ba}$ & 2,71 \\
120 & $37,74 \mathrm{Aa}$ & $38,97 \mathrm{Aa}$ & 2,69 \\
DMS & 2,72 & 2,68 & \\
\hline
\end{tabular}

Médias seguidas de mesma letra, maiúsculas nas linhas e minúsculas nas colunas, não diferem entre si pelo teste Tukey a $5 \%$ de probabilidade.

e uniformidade de distribuição da calda, mas essas gotas podem evaporar em condições de baixa umidade relativa ou serem levadas pela corrente de ar. WOMAC (1999) relata os fatores que influenciam o espectro de gotas produzido, dentre eles, destaca a pressão do líquido.

Dessa forma, para culturas em que o dossel é mais aberto, o uso de gotas maiores pode ser vantajoso, pois, além de requerer menor pressão, também propicia aplicação mais eficiente e ambientalmente correta. No caso deste trabalho, possivelmente a diminuição do tamanho das gotas oriundas da ponta XR 110.02 influiu negativamente na cobertura porcentual, visto o aumento de potencial de deriva e evaporação. Apesar da velocidade do vento durante a realização do experimento ser considerada adequada (entre 1,5 e $4,5 \mathrm{~km} \mathrm{~h}^{-1}$ ), seu efeito é maior nas gotas menores. $\mathrm{O}$ mesmo resultado não foi observado por CUNHA et al. (2004), os quais relataram que, nos bicos de jato plano, o aumento da pressão provocou diminuição do tamanho das gotas e, consequentemente, aumento da densidade de gotas e da cobertura do alvo.

\section{CONCLUSÃO}

Com base nos resultados encontrados neste trabalho, pode-se concluir que: as folhas superiores receberam maiores percentuais de cobertura do que as folhas posicionados no dossel inferior da cultura; 0 aumento da taxa de aplicação de $120 \mathrm{~L} \mathrm{ha}^{-1}$ para $160 \mathrm{~L}$ ha $^{-1}$ resulta em pequena diminuição da cobertura somente para a ponta XR 110.02, em virtude da redução do tamanho das gotas.

\section{REFERÊNCIAS}

ANTUNIASSI, U.R. et al. Avaliação da cobertura de folhas em aplicacões terrestres com diferentes tipos de pontas. In: SIMPÓSIO INTERNACIONAL DE TECNOLOGIA DE APLICAÇÃO DE
AGROTÓXICOS, 3., 2004. Botucatu, SP. Anais... Botucatu: FEPAF, 2004. p.48-51. 1 CD-Rom.

BALAN, M.G. et al. Pulverização em alvos artificiais: avaliação com o uso do software conta-gotas. Ciência Rural, Santa Maria, v.35, n.4, p.916-919, 2005.

BRASIL. Ministério da Agricultura, Pecuária e Abastecimento. Ferrugem laranja ameaça iminente aos canaviais brasileiros Brasília, 2008. (Boletim Técnico).

CANTERI, M.G. et al. SASM - Agri: sistema para análise e separação de médias em experimentos agrícolas pelos métodos ScoftKnott, Tukey e Duncan. Revista Brasileira de Agrocomputação, Ponta Grossa, v.1, n.2, p.18-24. 2001. Disponivel em: <http://www. agrocomputacao.deinfo.uepg.br/dezembro_2001/Arquivos/RBAC_ Artigo_03.pdf>. Acesso em: 08 jun. 2012.

CUNHA, J.P.A.R. et al. Aplicação aérea e terrestre de fungicida para o controle de doenças do milho. Revista Ciência Agronômica, Fortaleza, v.41, n.3, p.366-372, 2010. Disponivel em: <http:// www.scielo.br/scielo.php?script=sci_arttext\&pid=S180666902010000300007\&lng=pt\&nrm=iso>. Acesso em: 08 jun. 2012. doi: $10.1590 / \mathrm{S} 1806-66902010000300007$.

CUNHA, J.P.A.R. et al. Espectro de gotas de bicos de pulverização hidráulicos de jato plano e de jato cônico vazio. Pesquisa Agropecuária Brasileira, Brasília, v.39, n.10, p.977-985, 2004. Disponivel em: <http://www.scielo.br/scielo.php?script=sci arttext\&pid=S0100-204X2004001000005\&lng=pt\&nrm=iso $>$. Acesso em: 08 jun. 2012. doi: 10.1590/S0100-204X2004001000005.

GERARD, A.J.M. et al. Towards predicting pesticide deposition from plant phenology; a study in spring barley. Pesticides Science, v.53, p.252-262, 1998. Disponivel em: <http://www. scielo.br/scielo.php?script=sci_nlinks\&ref=000059\&pid=S0100$8358200500020002000005 \& \operatorname{lng}=e n>$. Acesso em: 08 jun. 2012. doi: 000059/S010083582005000 20002000005.

IBGE (Instituto Brasileiro de Geografia e Estatística). Levantamento Sistemático da Produção Agrícola. Acesso em: 16 nov. 2010. Online. Disponível em: <http://www.ibge.gov.br/ home/estatistica/indicadores/agropecuaria/ lspa/defaulttab.shtm>.

KÖPPEN, W.; GEIGER, R. Klimate der erde. Gotha: Verlag Justus Perthes, 1928. Wall-map $150 \mathrm{~cm} \times 200 \mathrm{~cm}$.

MATTHEWS, G.A. Pesticide application methods. 2.ed. London: Longman, 2002. 405p. Disponivel em: <http://www. 
scielo.br/scielo.php?script=sci_nlinks\&ref=000082\&pid=S0100$6916200400020001500007 \& \operatorname{lng}=e n>$. Acesso em: 08 jun. 2012. doi: 000082/S01006816200400020001500007.

PEREIRA, J.M. et al. Efeito fisiológico do inseticida thiamethoxam na cultura da cana-de-açúcar. Arquivos do Instituto Biológico, São Paulo, v.77, n.1, p.159-164, 2010.

ROMÁN, R.A.A. et al. Cobertura da cultura da soja pela calda fungicida em função de pontas de pulverização e volumes de aplicação. Scientia Agraria, Curitiba, v.10, n.3, p.223-232, 2009. Disponivel em: <http://ojs.c3sl.ufpr.br/ojs2/index.php/agraria/ article/view/14529>. Acesso em: 08 jun. 2012.

SANTOS, R.O. Níveis de deposição de produtos líquidos com aplicação aérea utilizando adjuvantes. 2007. 49f. Dissertação (Mestrado Engenharia Agrícola - Máquinas e Automação Agrícola) - Universidade Federal de Lavras, MG.

SCORALERT. Sugarcane orange rust alert system. Notícias. Acesso em: 17 nov. 2010. Online. Disponível em: http://scoralert. com/listaNoticias.aspx.

SIDAHMED, M.M. Analytical comparison of force and energy balance methods for characterizing sprays from hydraulic nozzles. Transactions of the ASAE, St. Joseph, v.41, n.3, p.531-536, 1998. Disponivel em: <http://www.scielo.br/scielo.php?script=sci_ nlinks\&ref $=000076 \&$ pid $=$ S0103-8478200600050000300011\&ln $\mathrm{g}=\mathrm{en}>$. Acesso em: 08 jun. 2012. doi: 000076/S01038478200600050000300011

SILVA, M.A. et al. Tipos de colheita e épocas de aplicação de glifosato na erradicação de soqueiras de cana-de-açúcar.
Pesquisa Agropecuária Brasileira, Brasília, v.41, n.1, p.4349, 2006. Disponivel em: <http://www.scielo.br/scielo. php?script=sci_arttext\&pid=S0100-204X2006000100007\&lng $=$ pt\&nrm=iso $>$. Acesso em: 08 jun. 2012. doi: 10.1590/S0100204X2006000100007.

SOUZA, R.T.et al. Depósito de pulverização com diferentes padrões de gotas em aplicações na cultura do algodoeiro. Engenharia Agrícola, Jaboticabal, v.27, n.esp, p.75-82, 2007. Disponível em: $<$ http://www.scielo.br/scielo.php?script=sci_arttext\&pid=S010069162007000200011\&lng=pt\&nrm=iso>. Acesso em: 08 jun. 2012. doi: 10.1590/S0100-69162007 000200011.

TEEJET, 2011. Bicos - Para área total. Acesso em: 25 jan. 2011. Online. Disponível em: <http://www.teejet.com/portuguese/home/ products/spray-products/broadcast-spray-nozzles.aspx >.

TEIXEIRA, M.M. Influencia del volumen de caldo y de la uniformidad de distribución transversal sobre la eficacia de la pulverización hidráulica. 1997. 310f. Tese (Doutorado em Agronomia) - Escuela Técnica Superior de Ingenieros Agrônomos, Universidad Politécnica de Madrid, Madrid.

WOMAC, A.R. et al. Measurement variations in reference sprays for nozzle classification. Transactions of the ASAE, v.42, p.609-616, 1999. Disponível em: <http://www.scielo.br/scielo. php?script=sci_nlinks\&ref $=000117 \&$ pid $=$ S0100-204X20040010 $0000500017 \& \operatorname{lng}=e n>$. Acesso em: 08 jun. 2012. doi: 000117/ s0100-204x200400100000 500017.

ZAMBOLIM, L. et al. O que os engenheiros agrônomos devem saber para orientar o uso de produtos fitossanitários. Viçosa: UFV, 2003. 376p. 